\title{
Cancer burden in Slovenia with the time trends analysis
}

\author{
Vesna Zadnik, Maja Primic Zakelj, Katarina Lokar, Katja Jarm, Urska Ivanus, Tina Zagar
}

Institute of Oncology Ljubljana, Epidemiology and Cancer Registry, Ljubljana, Slovenia

Radiol Oncol 2017; 51(1): 47-55.

Received 6 January 2017

Accepted 14 January 2017

Correspondence to: Assoc. Prof. Vesna Zadnik, M.D., Ph.D., Zaloška 2, SI-1000 Ljubljana, Slovenia. Phone: +386 1587 9451;

Fax: +386 1587 9400; E-mail: vzadnik@onko-i.si

Disclosure: No potential conflicts of interest were disclosed.

Background. The aim of our study was to describe cancer burden and time trends of all cancers combined, the most frequent as well as the rare cancers in Slovenia.

Patients and methods. The principal data source was the population-based Cancer Registry of Republic of Slovenia. The cancer burden is presented by incidence and prevalence for the period 1950-2013 and by mortality for years 1985-2013. The time trends were characterized in terms of an average annual percent change estimated by the log-linear joinpoint regression. The Dyba-Hakulinen method was used for estimation of incidence in 2016 and the projections of cancer incidence for the year 2025 were calculated applying the Globocan projection software. Results. In recent years, near 14,000 Slovenes were diagnosed with cancer per year and just over 6,000 died; more than 94,000 people who were ever diagnosed with cancer are currently living among us. The total burden of cancer is dominated by five most common cancer sites: skin (non-melanoma), colon and rectum, lung, breast and prostate, together representing almost $60 \%$ of all new cancer cases. On average the incidence of common cancers in Slovenia is increasing for $3.0 \%$ per year in last decade, but the incidence of rare cancers is stable.

Conclusions. Because cancer occurs more among the elderly, and additionally more numerous post-war generation is entering this age group, it is expected that the burden of this disease will be growing further, even if the level of risk factors remains the same as today.

Key words: cancer burden; cancer incidence; time trend; Cancer Registry of Republic of Slovenia

\section{Introduction}

Cancer is a growing public health challenge in Europe, with substantial and persistent inequalities in the incidence, mortality and survival within and between Member States. ${ }^{1}$ There were 14.1 million new cancer cases, 8.2 million cancer deaths and 32.6 million people living with cancer (within 5 years of diagnosis) in 2012 worldwide. ${ }^{2}$ Europe comprises only one eight of the total world population but has around one quarter of the global total number of cancer cases. ${ }^{1,3}$ Without effective interventions (comprehensive cancer prevention and control policies) the burden of cancer will increase dramatically. ${ }^{4}$ Almost 200 cancer registries are established only in Europe with the same goal of monitoring the burden of disease and the effectiveness of cancer control measures.5,6

Slovenia has a long tradition in establishing cancer control and it has one of the oldest populationbased cancer registries in Europe - Cancer Registry of Republic of Slovenia (CRS) that was founded in 1950 at the Institute of Oncology Ljubljana. Notification of cancer has been compulsory in Slovenia since the foundation of the CRS and is prescribed by law. ${ }^{7}$ The main source of data are notifications of cancer, gathered from all hospitals and diagnostic centres in Slovenia, exceptionally also from primary health care centres in case the patient has not been referred for further diagnostic investigations and/or treatment. Since 2010, regular annual reports ${ }^{7}$ of CRS are supported by web- 
portal SLORA (www.slora.si/en), where on-line analyses of CRS data are available. ${ }^{8}$

The data on cancer, that are collected by the CRS, incidence, survival and prevalence, serve together with mortality data, collected by the National Institute of Public Health as the basis for assessing the cancer burden in the country. They are important for planning and evaluation of all levels of cancer control: primary prevention, diagnosis, treatment, palliation and rehabilitation, for planning facilities and funding needed for cancer control (personnel, equipment and hospital capacities). Furthermore, they are basis for clinical and epidemiological research in Slovenia and in international multicentre studies as well as for evaluation of effectiveness of cancer screening programs..$^{5-7}$

In Slovenia, all patients with cancer have equal access to quality treatment, which is completely covered by obligatory health insurance. Primary care is provided by health care centres and general practitioners included in the public network. Secondary health care is provided by 11 general hospitals, two tertiary Clinical Centres, in Ljubljana and Maribor and Golnik Clinic. The Institute of Oncology Ljubljana, founded in 1938, is the only national comprehensive centre for cancer diseases, involved also in research and education. Common cancers are treated in general hospitals also, but the Institute is the referral centre for rare cancers; furthermore, radiotherapy is administered only there. ${ }^{9}$ It was estimated that health-care costs of cancer per person in Slovenia is around $70 \%$ of the European average cancer case costs. ${ }^{10}$ Since 2010, the National Cancer Control Programme is aimed to improve all aspects of cancer prevention and care in Slovenia. ${ }^{11,12}$

In this study we are presenting the incidence, mortality and prevalence data collected by the Cancer Registry of Republic of Slovenia in order to describe cancer burden together with the existing time trends and projections in Slovenia, complementing the Annual Reports and SLORA web portal data.

\section{Patients and methods}

The basic data source of our analysis is the population-based Cancer Registry of the Republic of Slovenia. The mortality data are provided by the National Institute of Public Health. All the data refer to all cancer patients, residents of Republic of Slovenia at the time of diagnosis, irrespective of where they have been treated or where they have died. The CRS' quality and completeness indices suggest that cancer registration in Slovenia adequately covers the entire population. To assure the completeness and to obtain additional information on registered cancer cases, CRS is linked with several governmental and health databases. Synchronisation of data between different sources is based on comparing unique personal identification number which is assigned to every resident in Slovenia and recorded in every state registry including CRS. Using unique personal identification number guaranties data integrity, data quality and prevents data duplication. CRS links with the Central Register of Population instantaneously through secure on-line connection (24/7 availability) and daily updates information on vital status and address for each person registered by CRS. The electronic linkage to the national Mortality Database and to the breast, colorectal and cervical screening registries is performed several times per year. ${ }^{13}$

The data on gender, date of diagnosis, age at diagnosis, code of primary site according to the International classification of Diseases $10^{\text {th }}$ edition, morphological code according to International Classification of Disease for Oncology $3^{\text {rd }}$ edition, vital status and cause of death for deceased were extracted from the CRS' database for all cancer cases. The cancer burden is presented by three basic epidemiological indicators: incidence, prevalence and mortality. Incidence and mortality are absolute numbers of all newly diagnosed cancer cases or number of deceased from cancer in individuals with permanent residence in Slovenia in one calendar year. New primary cancers of the same histology in paired organs, e.g. in the left and right breast, are not comprised in the incidence figures, neither are any new cancers of the same histology appearing in the same organ, e.g. multiple lesions of the colon. Prevalence is the number of all cancer patients that are alive on a given date, regardless of when they were diagnosed with cancer. Lifetime cancer prevalence is defined as all persons living and had ever been diagnosed with cancer, while partial prevalence counts only those patients, diagnosed with cancer within a defined period of time e.g. 1, 5 or 10 years before the date on which prevalence is calculated. Incidence and prevalence measures are available for the period from 1950 to 2013, the mortality measures since 1985.

Incidence rates were age standardised using the world standard population ${ }^{14}$ and represent the hypothetical crude rate assuming that the age struc- 
ture in the observed (Slovenian) population is the same as in the standard population, i.e. if the age structure of the population would remain the same over the time. The time trends were analysed using the log-linear joinpoint regression on age standardised incidence and mortality rates, implemented in the Joinpoint Regression program..$^{15}$ The trends were characterized in terms of an average annual percent change (APC) of the incidence and mortality rates, assuming the rates change at a constant percentage every year in the analysed time period.

The method by Dyba and Hakulinen ${ }^{16}$ was used for estimation of incidence in 2016. This model includes patients according to the period of diagnosis and their age at diagnosis for the last ten registered years. The population age structure was fitted for the current year (2016), provided by Statistical Office of the Republic of Slovenia. Projections of cancer incidence for the year 2025 were calculated applying the Globocan projection software. ${ }^{2}$ The expected number of new cancer cases was computed by multiplying the age-specific incidence rates estimated for 2012, by the expected population (size and age structure) for 2025. This analysis assumes that recent trends in cancer incidence will continue and that predictions of the size and age structure of the future population of Slovenia are accurate.

\section{Results and discusion}

\section{Cancer burden}

In Slovenia in the year 2013 there were 13,717 $(666 / 100,000)$ patients newly diagnosed with cancer, 7,442 $(730 / 100,000)$ males and 6,275 $(604 / 100,000)$ females. According to the EUCAN estimates Slovenia ranked in the $8^{\text {th }}$ place among 40 European countries in 2012 considering all cancer sites incidence. ${ }^{3}$ At the end of December 2013, there were 94,073 people $(41,607$ males and 52,466 females) alive who were diagnosed with one or more cancers at any time since the foundation of the CRS. One-year partial prevalence which includes patients, diagnosed with cancer within one year before the date of calculation was 11,101. This reflects the number of patients which are currently in the process of their primary oncological management. Further on, there were 31,148 patients included in the regular follow-up (1-4 years prevalence). According to the official data on cancer mortality 6,075 $(295 / 100,000)$ patients died from cancer in 2013 in Slovenia; 3,392 (333/100,000) males and 2,679 (258/100,000) females. According

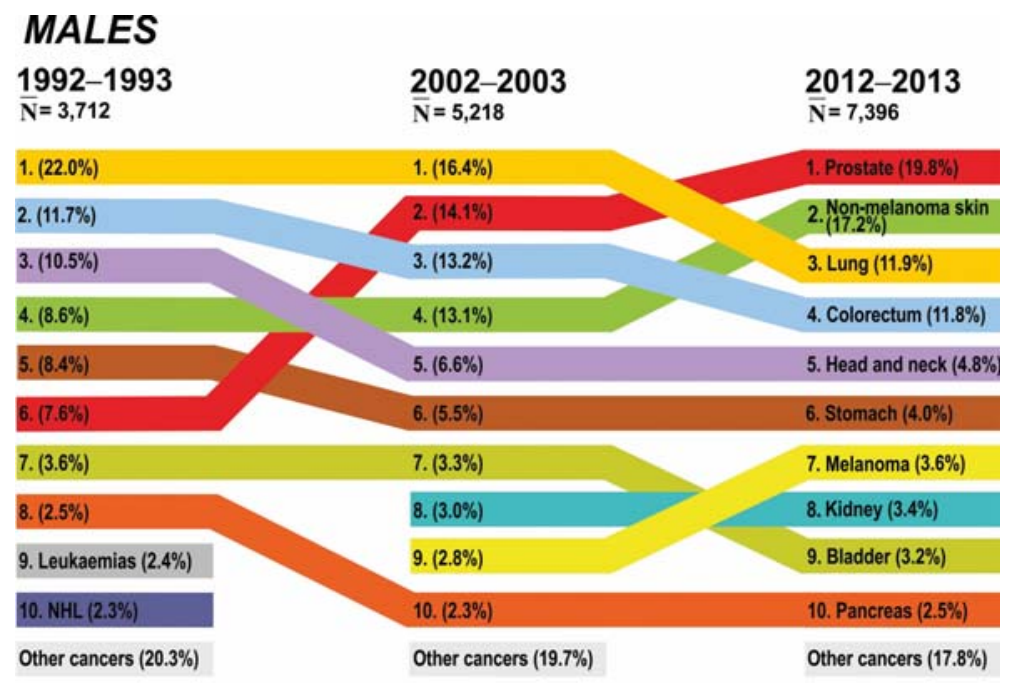

\section{FEMALES}

\begin{tabular}{|c|c|c|}
\hline$\overline{\mathbf{N}}=3,562$ & $\bar{N}=4,976$ & $\bar{N}=6,208$ \\
\hline 1. $(20.8 \%)$ & 1. $(21.8 \%)$ & 1. Breast $(20.6 \%)$ \\
\hline 2. $(11.4 \%)$ & 2. $(15.8 \%)$ & $\begin{array}{l}\text { 2. Non-melanoma skin } \\
(20.2 \%)\end{array}$ \\
\hline 3. $(10.9 \%)$ & 3. $(10.6 \%)$ & 3. Colorectum ( $9.4 \%)$ \\
\hline 4. $(6.5 \%)$ & 4. $(5.9 \%)$ & 4. Lung(6.6\%) \\
\hline 5. $(5.5 \%)$ & 5. (5.5\%) & 5. Corpus uteri (5.2\%) \\
\hline 6. $(4.8 \%)$ & 6. Cervix uteri $(4.0 \%)$ & 6. Melanoma (4.1\%) \\
\hline 7. $(4.6 \%)$ & 7. $(3.8 \%)$ & 7. NHL (3.1\%) \\
\hline 8. $(4.5 \%)$ & 8. $(3.6 \%)$ & 8. Stomach $(2.8 \%)$ \\
\hline 9. $(2.9 \%)$ & 9. $(3.3 \%)$ & 9. Pancreas $(2.7 \%)$ \\
\hline 10. $(2.5 \%)$ & 10. $(2.5 \%)$ & 10. Ovary $(2.7 \%)$ \\
\hline Other cancers $(25.7 \%)$ & Other cancers $(23.2 \%)$ & Other cancers $(22.4 \%)$ \\
\hline 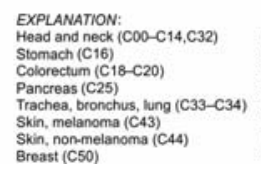 & $\begin{array}{l}\text { Cervix uteri (C53) } \\
\text { Corpus uteri (C54) } \\
\text { Ovary (C56) } \\
\text { Prostato (C61) } \\
\text { KKidney with renal pelvis (C64-C65) } \\
\text { Bladder (C67) } \\
\text { NHL' non-Hookgin's lymphoma (C82-C85) } \\
\text { Leukaemias (C91-C95) }\end{array}$ & \\
\hline
\end{tabular}

FIGURE 1. Cancer incidence - ten leading cancer sites with percentage distribution by gender, Slovenia 1992-1993, 2002-2003 and 2012-2013.

to the EUCAN estimates Slovenia ranked in the $8^{\text {th }}$ place among 40 European countries in 2012 considering all cancer sites mortality. ${ }^{3}$

The total burden of cancer is dominated by five most common cancer sites: skin (non-melanoma), colon and rectum, lung, breast and prostate, representing almost $60 \%$ of all new cancer cases. Cancers of these sites are associated with unhealthy lifestyle, such as excessive sunbathing, unhealthy diet, smoking and excessive alcohol consumption; the aim of primary prevention is to lower the risk associated with these factors. Figure 1 shows ten 


\section{MALES}

\begin{tabular}{|c|c|c|}
\hline $\begin{array}{l}1992-1993 \\
N=2,478\end{array}$ & $\begin{array}{l}2002-2003 \\
\bar{N}=2,816\end{array}$ & $\begin{array}{l}2012-2013 \\
\bar{N}=3,328\end{array}$ \\
\hline 1. $(29.4 \%)$ & 1. $(26.1 \%)$ & 1. Lung (22.9\%) \\
\hline 2. $(11.4 \%)$ & 2. $(13.5 \%)$ & 2. Colorectum (13.3\%) \\
\hline 3. $(11.1 \%)$ & 3. $(10.6 \%)$ & 3. Prostate $(11.4 \%)$ \\
\hline 4. $(8.2 \%)$ & 4. $(7.9 \%)$ & 4. Stomach $(6.1 \%)$ \\
\hline 5. $(7.4 \%)$ & 5. $(5.9 \%)$ & 5. Head and neck (5.5\%) \\
\hline 6. $(4.1 \%)$ & 6. $(4.3 \%)$ & 6. Pancreas (5.3\%) \\
\hline 7. Oesophagus (3.3\%) & 7. $(3.4 \%)$ & 7. Liver (4.8\%) \\
\hline 8. $(3.1 \%)$ & 8. $(3.3 \%)$ & 8. Bladder (3.8\%) \\
\hline 9. $(2.6 \%)$ & 9. $(2.6 \%)$ & 9. Kidney (3.5\%) \\
\hline 10. $(2.4 \%)$ & 10. $(2.6 \%)$ & 10. Leukaemias $(3.0 \%)$ \\
\hline Other cancers $(17.1 \%)$ & Other cancers $(19.6 \%)$ & Other cancers $(20.4 \%)$ \\
\hline
\end{tabular}

\section{FEMALES}

\begin{tabular}{|c|c|c|}
\hline$\overline{\mathbf{N}}=1,996$ & $\bar{N}=2,202$ & $\bar{N}=2,618$ \\
\hline 1. $(19.4 \%)$ & 1. $(18.1 \%)$ & 1. Breast (15.4\%) \\
\hline 2. $(13.1 \%)$ & 2. $(14.0 \%)$ & 2. Lung $(13.2 \%)$ \\
\hline 3. $(9.4 \%)$ & 3. $(11.2 \%)$ & 3. Colorectum (12.7\%) \\
\hline 4. $(7.8 \%)$ & 4. $(6.5 \%)$ & 4. Pancreas $(6.8 \%)$ \\
\hline 5. $(5.8 \%)$ & 5. $(5.5 \%)$ & 5. Stomach $(5.7 \%)$ \\
\hline 6. $(4.6 \%)$ & 6. $(5.3 \%)$ & 6. Ovary $(5.2 \%)$ \\
\hline 7. $(4.1 \%)$ & 7. $(2.8 \%)$ & 7. CNS $(3.1 \%)$ \\
\hline 8. Leukaemias $(3.2 \%)$ & 8. $(2.7 \%)$ & 8. Leukaemias $(2.8 \%)$ \\
\hline 9. Cervix uteri $(2.7 \%)$ & $\begin{array}{l}\text { 9. Gallblader and } \\
\text { billary tract ( } 2.5 \%)\end{array}$ & 9. Liver (2.8\%) \\
\hline 10. $(2.5 \%)$ & 10. $(2.5 \%)$ & 10. NHL (2.8\%) \\
\hline Other cancers $(27.5 \%)$ & Other cancers $(29.0 \%)$ & Other cancers $(29.5 \%)$ \\
\hline
\end{tabular}

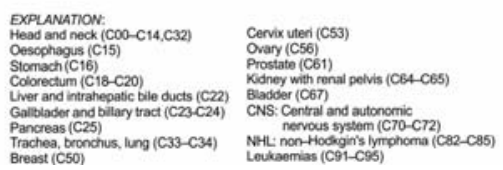

FIGURE 2. Cancer mortality - ten leading cancer sites with percentage distribution by gender, Slovenia 1992-1993, 2002-2003 and 2012-2013.

leading cancer sites with percentage distribution in three consecutive periods in Slovenia, separately for males and females. In 2013 1,485 males (20\%) were diagnosed with prostate cancer in Slovenia, being the most common diagnosis in males, compared to the $6^{\text {th }}$ place and less than $8 \%$ two decades ago. Lung cancer represents nowadays only $12 \%$ of all cancers in males (ranks $3^{\text {rd}} ; 869$ new cases), but in previous periods it was the most common male cancer representing more than $20 \%$ of all cancers. In females in all three time periods breast is the leading cancer site with $20 \%$ of all cancer cases. In 2013 1,252 females were diagnosed with breast cancer in Slovenia. Non-melanoma skin cancer is gaining its share in female population and it is approaching breast cancer in the most recent period. Lung cancer incidence in females is disturbingly climbing - from $8^{\text {th }}$ place and having a share of $4.5 \%$ two decades ago it now represents $6.6 \%$ of all newly diagnosed cases and occupying $4^{\text {th }}$ place.

Ten leading cancer sites according to the mortality shares are presented in Figure 2. The non-melanoma skin cancer is rarely fatal and is not part of this list, although it is among four most common cancer diagnoses. Almost one quarter (23\%) of all cancer deaths in males in Slovenia are due to lung cancer (748 deaths in 2013 in Slovenia). Another quarter of cancer death is attributed to colorectal (468 deaths in 2013) and prostate cancer (371 deaths in 2013); other cancer types cause much less cancer deaths. In females $40 \%$ of cancer deaths are attributed to breast (410 deaths in 2013 in Slovenia), lung (340 deaths in 2013) and colorectal (327 deaths in 2013) cancer. Supplementary material provides further epidemiological data for all cancers combined and for 15 most common cancer sites for the period 2009-2013 in Slovenia (SupMat 1-16).

Cancers of other sites are quite rare. In the contrast to the common definition of rare disease (prevalence less than 50/100,000), the experts from the project Surveillance of Rare Cancers in Europe $(\text { RARECARE })^{17}$ defined the rare cancer as any cancer with crude incidence rate less than 6 per 100,000 inhabitants. According to this definition 198 groups of rare cancer were identified. They are further joined into 65 groups, which are listed in the supplementary material (SupMat 17), and further into 15 categories as defined by the RARECARE project, the later are shown on Figure 3. All rare cancers combined account for $23 \%$ of all cancers in Slovenia in period 2004-2013: annually there are around 2,880 new rare cancers $(142 / 100,000)$. The rare cancer is most frequently diagnosed in digestive organs, following by head and neck, female genital organs and haematological tissue. In comparison to common cancers, rare cancers occur more often in childhood and adolescence. As in any rare disease also in rare cancers the low incidence is the main obstacle to conduct clinical trials needed to investigate and develop effective treatments. One way to overcome this obstacle would be to precisely monitor the rare cancer burden on population level and establish centres of excellence for diagnosis and treatment. ${ }^{17}$

The burden of cancer varies with age. Cancer is mostly the disease of the elderly since for the vast majority of cancers, incidence increases with age. 
From all patients diagnosed in 2013 61\% males and $58 \%$ females were aged 65 or more at diagnosis. From those born in 2013, one in two males and one in three females are expected to develop cancer by their age of 74 in Slovenian population. Cancer is a rare disease until the age of 19 years $(0.6 \%$ of all cancer cases in 2013). In childhood and adolescence, the most frequent type of cancer is leukaemia. Only 1.7\% of all cancers in 2013 occurred among people in the age group 20-34 years, where the most frequent malignancies are testicular cancer in males and cervical cancer in females. Among cancer patients, there is a predominance of females in the age group 35-49 years, while this ratio is reversed for the age group 50-74. Between 35-49 years, the most frequent types of malignancies in males are oral and lung cancers, while in females, breast and cervical cancers. Colorectal cancer becomes the predominant form of cancer for both sexes in the age group 50-74 years, while among older males (75+ years) prostate cancer is most frequently diagnosed. After the age of 75 years, there is a higher proportion of cancers among females, partially because of their longer life expectancy, with breast, colorectal and stomach cancers being the most common at this age.

\section{Time trend analysis}

The time trends of cancer burden in Slovenia for the last 64 years are summarized in tables and graphs available as the supplementary material (SupMat 1). Since 1950, the crude cancer incidence rate in Slovenia increased by $700 \%$ in males and by $470 \%$ in females. In the last 10 years, the average annual increase in males was $2.8 \%$ and $1.6 \%$ in females. Correspondingly, the average annual increase in age standardised incidence rate in males was $0.8 \%$ and $0.6 \%$ in females in the last 10 years. By comparing crude incidence rate to the age standardised rate where the standard population is taken to be the age structure of the Slovenian population in first year for which the graph is prepared (1961) we can assume that more than half of the crude incidence rate increase is a consequence of ageing of the population. The increase in crude mortality rate in the last 10 years was substantially slower; on average by $1.5 \%$ per year in males and by $1.7 \%$ in females. When we calculate the hypothetical rates in case, the Slovenian population would not age, the trend becomes reverse as the age standardised mortality rate is decreasing on average by $1.2 \%$ annually in males and by $0.5 \%$ in females in the last 10 years. The decreasing mortality despite increas-
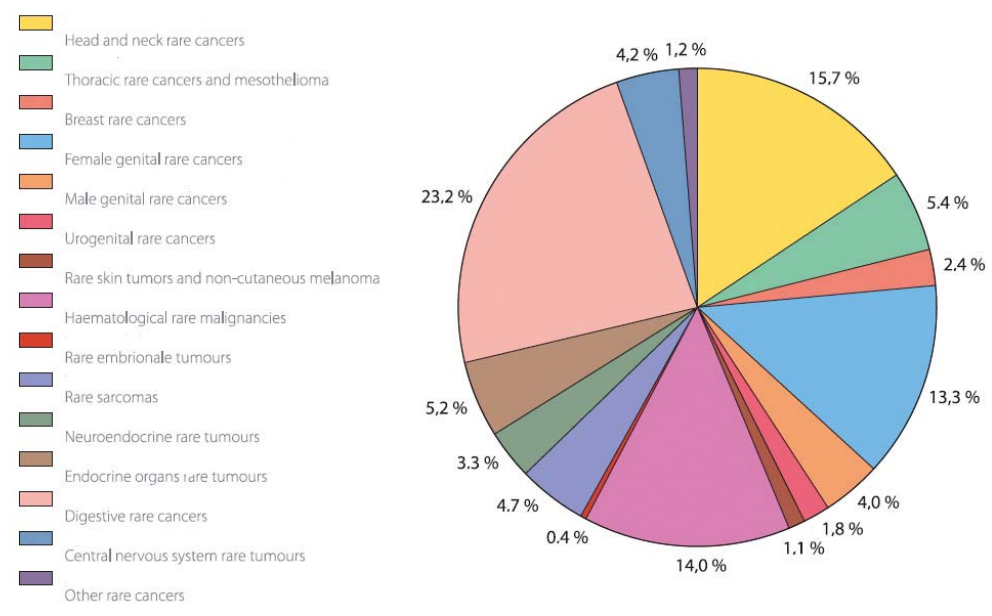

FIGURE 3. Rare cancers categorized in 15 groups, Slovenia 2004-2013.
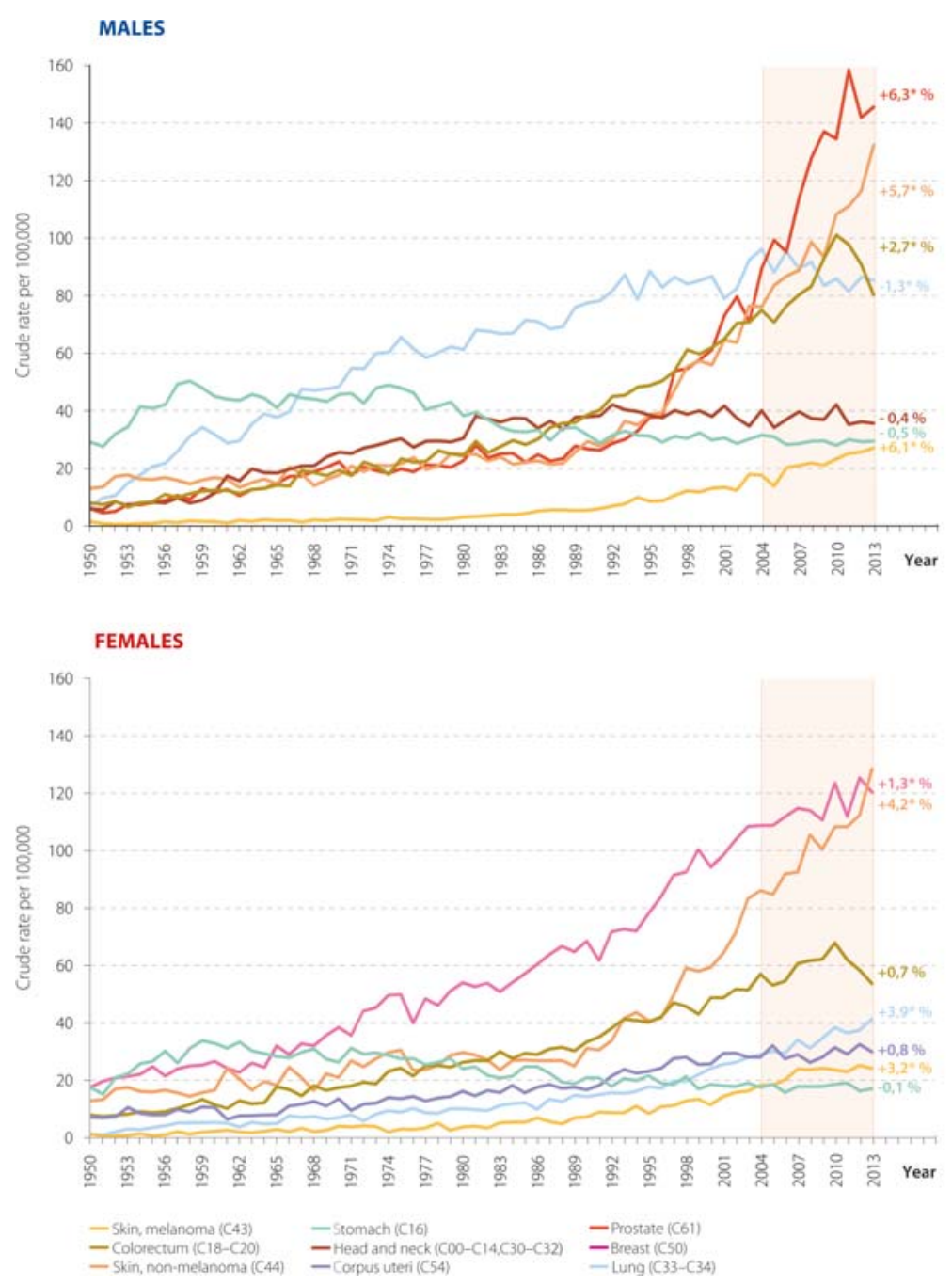

FIGURE 4. Trend of crude incidence rates of selected primary cancer sites by gender with average annual percent change in last 10 years, Slovenia 1950-2013. 


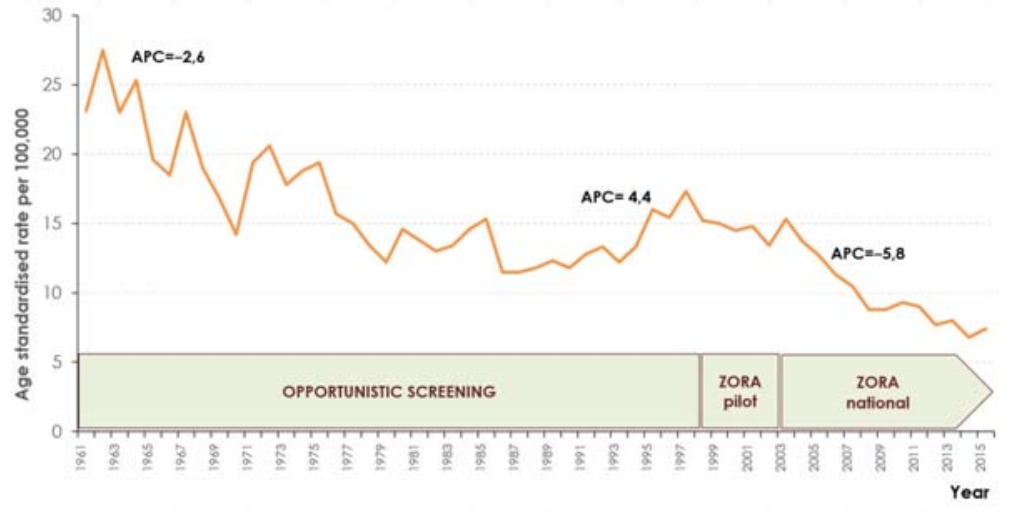

FIGURE 5. The age standardised cervical cancer incidence rates (world standard), Slovenia 1961-2015. The timeline of cervical cancer screening modalities and the average annual percent changes (APC) for the statistical significant cervical cancer incidence time trends (1961-1989, 1989-1997 and 2003-2015) are indicated.

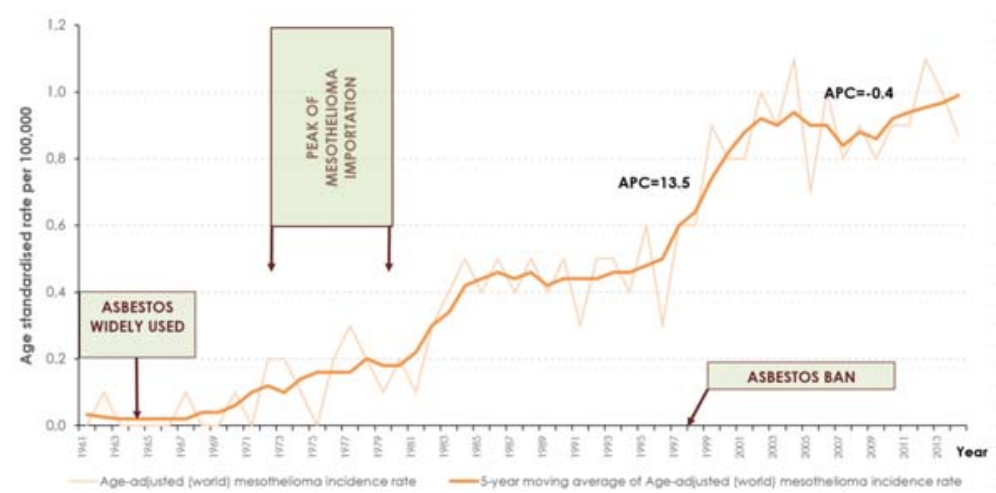

FIGURE 6. The age standardised mesothelioma incidence rates (world standard) with 5-year moving averages, Slovenia 1961-2014. The average annual percent changes (APC) are presented for the most important time segments (1998-2003 and 2003-2014) and critical years of asbestos exposure are marked.

ing incidence indicates improvement in treatment of cancer patients. It is a proof that more and more are cured of or living with and not dying from cancer.

The long-term time trends of the incidence for most common cancers by gender are plotted in Figure 4. The APCs in last 10 years are included. In males the lung cancer incidence was increasing till the beginning of the nineties, while it became stable onwards (85/100.000) and is slowly decreasing (on average by $1.3 \%$ per year) and was finally overcome by prostate cancer (average increase by $6.3 \%$ per year). The huge increase in prostate cancer incidence rate in the last years is not due to some new risk factor, but more frequent use of prostate specific antigen (PSA) test as an opportunistic screening method $^{9}$, resulting in detection of many cancers that would have never progressed or would even not have been detected during lifetime without screening, because the person would not develop any health problems.

The changes in the colorectal cancer incidence should be interpreted taking into consideration the changes in the diagnostic practice - in Slovenia the National colorectal cancer screening programme (SVIT) has been introduced in 2009. ${ }^{18}$ The average annual increase in colorectal cancers in males in the period 2004-2011 was 5.3\%, but there was a decrease of $10.5 \%$ in the following years 2011-2013, attributable to treatment of precancerous polyps that would have progressed to cancer if person would not respond to the screening invitation. In females, the incidence rate of breast, lung and nonmelanoma skin cancer is increasing. Like in males also in females the colorectal cancer incidence time trends have been changed because the national screening programme SVIT has been introduced: in the period 2004-2010 the incidence increased for $3.6 \%$ annually, but in the years 2010-2013 it decreased by $6.4 \%$.

The effect of population-based screening is even more pronounced in the case of cervical cancer. Slovenia is one of the European countries with the highest historical incidence of cervical cancer and also one of the countries with the highest decrease of cervical cancer incidence over time. ${ }^{19}$ As presented in Figure 5, the highest peak of the cervical cancer incidence was registered in the population based CRS in year 1962 when 286 new cases were diagnosed and age standardised incidence rate was $27.5 / 100,000$. The incidence was then decreasing till the end of the eighties by $2.6 \%$ per year on average, most likely due to the effect of the opportunistic screening. At the beginning of the nineties, the cervical cancer incidence trend has changed again with a second peak in 1997, which triggered the introduction of organised population-based cervical cancer screening programme ZORA. In 1998 and 2001 two pilot programmes of organised screening were implemented in Central and CoastalKarst Slovenian region. The steepest decrease of incidence was observed after the implementation of programme ZORA at the national level in 2003 with APC being 5.8 in the period 2003-2015. The lowest incidence of cervical cancer to this year was registered in 2014 when 114 new cases were diagnosed and age standardised incidence rate was 6.8/100,000, which presents a difference of $-20.7 / 100,000$ in comparison with the highest recorded age standardised incidence rate in $1962 .{ }^{20}$

On average the incidence of common cancers in Slovenia is increasing for $3.0 \%$ each year. On 
the contrary, in the group of rare cancers the incidence in stable - for all rare cancers combined the APC for the period 2004-2013 is 0.5 (SupMat 18). Nevertheless, also among rare cancers there are some specific cancer types with significant variation in incidence rate over time. One of them is malignant mesothelioma. Till the end of 2013 there were 729 mesothelioma cases registered in the population based CRS, 518 (71\%) of them among men. In the period 2009-2013 there were 1.9 mesothelioma cases per 100,000 inhabitants in Slovenia; $2.8 / 100,000$ in male population. The age standardised mesothelioma incidence rates with 5-year moving averages for the period 1961-2014 are shown in Figure 6. From 1970 on the mesothelioma incidence is irregularly increasing: the steepest increase can be observed from 1998 to 2003 (APC = 13.5). After the year 2004 the mesothelioma time trend curve is stable (APC $=-0.4)$. In a recent ageperiod-cohort analysis of the presented data the highest mesothelioma risk was detected for the cohort born between 1940 and $1944 .{ }^{21}$ The peak value of asbestos importation in $1973^{22}$ corresponds to the peak of mesothelioma incidence curve exactly 30 years later.Considering the latency between asbestos exposure and mesothelioma development, which is around 40 years ${ }^{23}$, these results imply that the mesothelioma peak has already been reached in Slovenia.

\section{Projections}

As CRS is using many data sources the data collection and preparation is delaying the report of cancer burden figures for 2 to 3 years. The numbers for 2013 are currently available and presented in our results. However, the estimation of the number of cancer cases was prepared for the current year, 2016. There will be 14,785 new cancer cases registered in the year 2016; 8,259 males and 6,527 females. The 2016 estimations with $95 \%$ confidence intervals for specific cancer sites are available in the supplementary material (SupMat 19). In males the number of head and neck, oesophageal, testicular and thyroid cancers is expected to be stable or even smaller. In females a smaller number is expected only for cervical cancer.

Long-term prediction of cancer incidence can help to plan cancer services and cancer control measures for the future. Due to the aging population the overall number of new cancer cases is predicted to increase further. The expected additional number of cases for some of common cancers in 2025 in Slovenia is presented in Figure 7, consider-

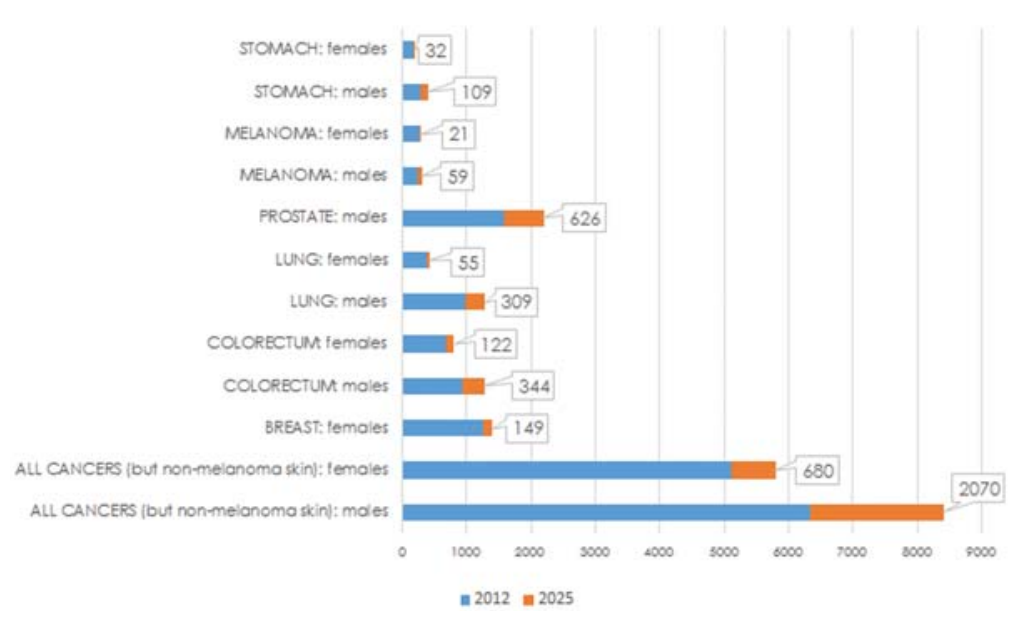

FIGURE 7. Cancer incidence of some common cancer sites in Slovenia in 2012 with the estimation of the number of expected additional cases in 2025 if only the population ageing is considered. ${ }^{2}$

ing only the ageing of population. The incidence of all cancers in males will increase for 32.7\% till 2025 and for $13.3 \%$ in females. In 10 years in Slovenia more than 17,000 new cancer cases are expected. It is important to note that this number does not include non-melanoma skin cancers, which is estimated to more than 2,000 additional incident cases. The increase of more than $30 \%$ is predicted for prostate, stomach, colorectal and lung cancers in males. There will be more than 600 additional prostate cancers and more than 300 additional colorectal and lung cancer cases in Slovenian male population in 2025. In females there will be only slight increase $(8 \%)$ in the number of melanoma cases. More than 100 additional cases are expected in breast and colorectal cancer.

The majority of predicted additional cases will be diagnosed in the elderly. Therefore, the median age at diagnosis will increase at population level. It is expected that in 2025 more the $70 \%$ of patients will be diagnosed at age 65 or more compared to $59 \%$ in 2013 . They will on average have more concomitant diseases and less favourable health related quality of life, which render specific oncological treatment more difficult or impossible to carry out. Hence, better palliative and adjusted specific oncological treatment should be the major priority in Slovenian health care system in the next years.

However, when predicting the future cancer burden, it is not enough to consider the ageing of population only. The number of incident cancer cases depends considerably also on the risk or protective factors to which the population is exposed. In the next ten years in Slovenia we expect that the 
results of the effective national smoking cessation programmes will manifest. In male population the proportion of adult male smokers has almost halved in the last thirty years ${ }^{24}$, which in turn will lead to less smoking related cancers among men. In females the smoking cessation is not evident in Slovenian population so far and increasing number of adolescents started smoking is of concern. National policy on healthy diet and physical activity should further contribute to lower risk of common cancers. ${ }^{9}$ In addition to success of primary preventions, the national organised cancer screening policy will have major impact on the number of new cancer patients as well as mortality from cancers for which population based screening programmes are established. Besides cervical and colorectal cancer screening, breast cancer screening will cover the whole female population in the target age group till the end of 2020, so decrease in breast cancer mortality is expected in the next decade. Considering the population ageing as well as the effects of primary and secondary prevention measures the cancer incidence is aimed to remain below 15,500 new cases in 2020 (9,000 in males and 6,500 in females) in the existing Slovenian National Cancer Control Plan. ${ }^{12}$

\section{Conclusion}

In 1981, Doll and Peto ${ }^{25}$ estimated the proportion of cancer deaths attributable to known risk factors. They judged that more than a third of cancer deaths were attributable to risk factors as consequence of unhealthy lifestyle. The most important are those that are the consequence of western way of life: obesity, diet with too much energy and low in vegetables and fruit, sedentary lifestyle together with smoking and high alcohol consumption.

Changing political and economic circumstances over the past decades, resulted in very different lifestyle for most Slovenes and their exposure to carcinogens in the working and living environment, but also led to changing health care organization. Since latent period in cancer is generally longer than 20 years, it can be concluded that the effects of these changes are not fully developed yet. ${ }^{26}$ In recent years, near 14,000 Slovenes were diagnosed with cancer per year and just over 6,000 died; more than 94,000 people who were ever diagnosed with cancer are currently living among us. Slovenian population is ageing - because cancer occurs more among older, and additionally more numerous post-war generation is coming to this ages, it is expected that the burden of this disease will be increasing further, even if the level of risk factors remained the same as today.

Control of the cancer burden can be established only by clear objectives, well-planned and financially supported interventions and constant monitoring of the quality and effectiveness of these actions. They should be summarised in national cancer control plans with well-established priorities. ${ }^{27}$ Cancer registries, a core component of cancer health information systems, have a major role in providing data to prioritize programmes in national cancer control plans as well as to monitor the progress of their implementation. In Slovenia, we are following these recommendations by the second National Cancer Control Programme, as well as with long-standing and good-quality cancer registry.

\section{Acknowledgements}

The authors thank the staff of the Cancer Registry of Republic of Slovenia whose efforts to collect accurate and complete data have made this report possible.

We express a sincere thankfulness to professors Matej Bračko, Marko Hočevar, Vera Pompe-Kirn, Primož Strojan and Branko Zakotnik for their careful review and commenting on the Slovenian cancer burden indicators issued in the Annual Report of the Cancer Registry of Republic of Slovenia.

\section{References}

1. Bray F. The burden of cancer in Europe. In: Coleman MP, Alexe D, Albreht T, McKee M, eds. Responding to the challenge of cancer in Europe. Ljubljana: Institute of Public Health of the Republic of Slovenia; 2008. p. 7-40.

2. GLOBOCAN 2012 v1.0, Cancer Incidence and Mortality Worldwide: IARC CancerBase No. 11 [Internet]. 2013 [cited 25.12.2016]. Available from: http://globocan.iarc.fr.

3. Ferlay J, Steliarova-Foucher E, Lortet-Tieulent J, Rosso S, Coebergh JW, Comber $\mathrm{H}$, et al. Cancer incidence and mortality patterns in Europe: estimates for 40 countries in 2012. Eur J Cancer 2013; 49: 1374-403. doi: 10.1016/j.ejca.2012.12.027

4. Coleman MP, Alexe D, Albreht T, McKee M, eds. Responding to the challenge of cancer in Europe. Ljubljana: Institute of Public Health of the Republic of Slovenia; 2008

5. Forsea AM. Cancer registries in Europe-going forward is the only option Ecancermedicalscience 2016; 10: 641. doi: 10.3332/ecancer.2016.641

6. Siesling S, Louwman WJ, Kwast A, van den Hurk C, O'Callaghan M, Rosso $\mathrm{S}$, et al. Uses of cancer registries for public health and clinical research in Europe: Results of the European Network of Cancer Registries survey among 161 population-based cancer registries during 2010-2012. Eur J Cancer 2015; 51: 1039-49. doi: 10.1016/j.ejca.2014.07.016

7. CRRS. Cancer in Slovenia 2013. Ljubljana: Institute of Oncology Ljubljana, Epidemiology and Cancer Registry, Cancer Registry of Republic of Slovenia; 2016. 
8. SLORA: Slovenia and Cancer [Internet]. Institute of Oncology Ljubljana, Epidemiology and Cancer Registry. 2010 [cited 15.12.2016]. Available from: http://www.slora.si/en.

9. Primic Zakelj M, Zagar T. The burden of cancer in Europe. In: Coleman MP, Alexe D, Albreht T, McKee M, eds. Cancer control in Slovenia: achievements, shortcomings and opportunities. Ljubljana: Institute of Public Health of the Republic of Slovenia; 2008. p. 279-96.

10. Luengo-Fernandez R, Leal J, Gray A, Sullivan R. Economic burden of cancer across the European Union: a population-based cost analysis. Lancet Oncol 2013; 14: 1165-74. doi: 10.1016/S1470-2045(13)70442-X

11. Ministry of Health RS. Slovene national cancer control programme 20102015. Ljubljana: Ministry of Health, Republic of Slovenia; 2010.

12. Ministry of Health RS. Slovene national cancer control programme 20172021. Ljubljana: Ministry of Health, Republic of Slovenia; 2017.

13. Zadnik V, Primic Zakelj M, Zagar T. Linkage to supplementary registration sources: key lessons learned in the last 30 years in Slovenia. In: Benider A, Zanetti R, Siesling S, Bray F, eds. The 38th Annual IACR Conference. Marrakech: IACR; 2016

14. Segi M. Cancer mortality for selected sites in 24 countries (1950-57). Sendai: Department of Public Health, Tohoku University of Medicine; 1960.

15. JPR. Joinpoint Regression Program, Version 4.0.4. Bethesda: Statistical Research and Applications Branch, National Cancer Institute; 2013.

16. Dyba T, Hakulinen T, Paivarinta L. A simple non-linear model in incidence prediction. Stat Med 1997; 16: 2297-309.

17. Gatta G, van der Zwan JM, Casali PG, Siesling S, Dei Tos AP, Kunkler I, et al. Rare cancers are not so rare: the rare cancer burden in Europe. Eur J Cancer 2011; 47: 2493-511. doi: 10.1016/j.ejca.2011.08.008

18. Tepeš B, Kasesnik K, Novak Mlakar D. Smernice programa SVIT. Slovenske smernice za zagotavljanje kakovosti presejanja raka debelega črevesa in danke. [Guidelines of Svit programme. National guidelines for quality insurance in colorectal screening; in Slovene]. Ljubljana: National Institute for Public Health; 2015.

19. Elfstrom KM, Arnheim-Dahlstrom L, von Karsa L, Dillner J. Cervical cance screening in Europe: Quality assurance and organisation of programmes. Eur J Cancer 2015; 51: 950-68. doi: 10.1016/j.ejca.2015.03.008

20. Ivanus U, Primic Zakelj $M$, eds. 6. izobraževalni dan programa ZORA. [6th educational day of the ZORA programme; in Slovene]. Ljubljana: Institute of Oncology Ljubljana; 2015.

21. Zadnik V, Primic Zakelj M, Jarm K, Zagar T. Time trends and spatial patterns in the mesothelioma incidence in Slovenia, 1961-2014. Submitted to Eur Cancer Prev. 2016.

22. Dodic Fikfak M, Sesok J. Nacionalne smernice za azbest. Zaključno poročilo projekta. [National guidelines for asbestos. Final report, in Slovene] Ljubljana: Institute of Public Health of the Republic of Slovenia; 1999.

23. Robinson BM. Malignant pleural mesothelioma: an epidemiological perspective. Ann Cardiothorac Surg 2012; 1: 491-6. doi: 10.3978/j.issn.2225 319X.2012.11.04

24. Maucec Zakotnik J, Tomsic S, Kofol-Bric T, Korosec A. Zdravje in vedenjsk slog prebivalcev Slovenije. Trendi v raziskavi CINDI 2001-2004-2008. [Health and lif style in Slovenian population. Trends from CINDI researches 2001 2004-2008; in Slovene]. Ljubljana: Institute of Public Health of the Republic of Slovenia; 2012.

25. Doll R, Peto R. The causes of cancer: quantitative estimates of avoidable risks of cancer in the United States today. J Nat/ Cancer Inst 1981; 66: 1191 308.

26. Zadnik V, Primic Zakelj M, Krajc M. Breme raka v Sloveniji v primerjavi drugimi evropskimi državami = Cancer burden in Slovenia in comparison with the burden in other European countries. Zdrav Vestn 2012; 81: 407 12.

27. Albreht T, Martin-Moreno JM, Jelenc M, Gorgojo L, Harris M, eds. European Guide for Quality National Cancer Control Programmes. Ljubljana: Nationa Institute of Public Health; 2015. 